\title{
3 Engaging Teachers and Researchers in Classroom Research: Issues of Fluidity and Time in Two Multi-Sited Projects
}

\author{
Marie Källkvist and Päivi Juvonen
}

\section{Introduction}

The need for efficient inclusion of migrants in their new home nations has led to explicit societal demands for more evidence-informed teaching practices, focusing, among other things, on providing equal opportunities and equity for language-minority students (Baker \& Wright, 2017; Cummins, 2018, this volume; García, 2009). This calls for more classroom-based research that addresses increasing language diversity in student and teacher populations. This, in turn, presupposes rigorous school and classroom research methodology, which is portrayed as inherently complex, involving multiple social agents such as teachers, students, researchers and sometimes caregivers (Baker \& Wright, 2017; Dörnyei, 2007; Mackey \& Gass, 2005; Schachter \& Gass, 1996; Spada, 2005). School-based research is also described as being time-consuming due to the fluidity of research participants and because schools are providers of education rather than sites to conduct research (Dörnyei, 2007). Mackey and Gass state that 'classroom research is a particularly complex and multifaceted endeavor that must be planned carefully', stressing 'the importance of flexibility' and the need for researchers to be 'patient, flexible, and ready to utilize alternative contingency plans' (2005: 212). According to Baker and Lewis (2015: 119), 'schools and classrooms have complex multi-causality, are ever dynamic and fluid, evolving and ever-changing, sometimes unpredictable and inconsistent'. The 'gold standard' of welldesigned experiments that allow for generalisation beyond the sample 
researched is normally unattainable as any study 'is still dependent on local conditions and is situated within a particular time. Students, teachers and instructional styles cannot be reduced to isolated variables and manipulated as if they were seeds in agricultural experimental research' (Baker \& Lewis, 2015: 119).

Classroom research, therefore, tends to rely on qualitative or mixedmethod data, which in turn means that participant sampling is 'purposive' (Cohen et al., 2011; Dörnyei, 2007), 'convenient' or 'opportunity' (Dörnyei, 2007). Thus, 'researchers handpick the cases to be included in the sample on the basis of their judgement of their typicality or possession of the particular charactertistics being sought [...] they build up a sample that is satisfactory to their specific needs' (Cohen et al., 2011: 156). This is the opposite of random sampling, which is associated with quantitative data collection, often aiming at generalisation beyond the sample studied (Dörnyei, 2007). Given that much classroom research involves qualitative data (Baker \& Wright, 2017), purposive/convenient/opportunity sampling can potentially be done in as many ways as there are studies. Referring to Rossiter (2001), Duff and Early (1996) and Schachter and Gass (1996), Dörnyei (2007: 177) points out that research reports and methodology texts underplay the difficulties of collecting data in classrooms. In encouraging more open discussion on 'the inherent difficulties of classroom investigation', Dörnyei (2007: 177) echoes Schachter and Gass, who assert that downplaying challenges is a 'disservice to other researchers, and particularly those with less experience’ (Schachter \& Gass, 1996: 26). This point from 1996 is still valid; in 2019, Patsy Lightbown and Nina Spada gave a plenary lecture at the American Association for Applied Linguistics, entitled 'In it together: Teachers, researchers and classroom SLA', providing 'illustrations of how the research process is conceptualized and how teachers are engaged in it' (Lightbown \& Spada, 2019), elaborating on and illustrating the engagement of teachers in their school research.

In this chapter, we provide data and illustration that address these underdescribed challenges of initiating and sustaining classroom research from the perspectives of two multi-sited linguistic ethnographies carried out in multilingual secondary schools. We focus on the challenging aspects of participant fluidity and time. The terms fluid and fluidity are borrowed from Baker and Lewis (2015: 119) and Dörnyei (2007: 188), by which we mean that the participant sample is likely to change through the attrition of some participants and the addition of others. Fluidity is caused by a range of factors: research relies on volunteers, who can withdraw their consent at any time; there is rarely $100 \%$ attendance in classrooms as students are away due to, for example, illness and dental and medical appointments; there is mobility among students as they may change schools or classes. The same applies to teachers and researchers, who also catch illnesses, go on leave for a variety of reasons and change jobs. Also, times of financial cutbacks can lead to additional attrition. Our second 
focus is time, discussed in Dörnyei (2007) and Spada (2005), with Spada stating that 'the time-consuming nature of classroom research is not a minor factor' (2005: 336). For the benefit of researchers who are planning classroom research, we illustrate the time needed to secure and sustain the engagement of teacher participants under different circumstances: through inviting both teachers who had been engaged in prior research projects as well as teachers who had not previously been research participants.

As cases, we use our own two linguistic-ethnography projects conducted in secondary schools over a four-year time period. Doing ethnography means engaging with 'a real social environment with real people' (Blommaert \& Dong, 2010: 22) over an extended time period. As discussed above, a number of things can go wrong in these scenarios, which warrants a realistic mindset on the part of researchers: '[p]art of this realism, and unfortunately often overlooked, is to have a Plan B' (Blommaert $\&$ Dong, 2010: 22, emphasis in original). In writing this chapter, we aim to contribute to the methodology literature by sharing details from the realities of conducting multi-sited, longitudinal classroom research. We describe (a) the amount of redundancy in teacher participants that was needed to secure the engagement of a sufficient number of focal teachers for data collection that extended over two and a half years, (b) the impact of teacher participant fluidity on the type of data eventually collected, and (c) the impact of researcher participant fluidity on the type of data collected and on time.

Both projects are team-based and driven by an inclusive-education agenda, recognising the need for educational practices that engage students' multilingual and multicultural repertoires, manifested as spontaneous translanguaging and/or pedagogical translanguaging (Creese \& Blackledge, 2010; García, 2009). We begin by reviewing existing researchmethodology publications on participant fluidity, followed by a presentation of the two projects for which we are principal investigators (PIs). In addressing issues of participant fluidity, we describe how we recruited, selected and retained teacher and researcher participants. We conclude by discussing the implications of participant fluidity for the original research designs and schedules, and for researcher and PI flexibility.

\section{Issues of Time and Participant Fluidity in Classroom Research}

Several aspects of school-based research combine in making it timeconsuming: applying and waiting for ethics approval, setting up meetings with the school management, teachers, their students and sometimes caregivers (Dörnyei, 2007), gaining participant consent and building trust so that participants remain committed (Spada, 2005). Trust is often built over the course of a descriptive research phase, often involving observation, recordings and interviews. In second-language acquisition (SLA) research, the descriptive phase often serves to pave the way for an 
intervention phase (Spada, 2005). Ethnographic classroom data collection also requires long-term engagement (Barwell, 2019).

When classroom research extends over time, the scene is set for fluidity, not only participant attrition, but also participant addition more or less suddenly, for example, when a new student joins the class or when a special-needs teacher shows up in the classroom. As to teacher participation in research, Dörnyei puts that

[f] or rigorous research we need a well-defined participant sample. This seemingly basic condition can be surprisingly difficult to achieve in school settings if the study involves more than a one-off cross-sectional survey [...] teachers can be very busy and stressed out, and they have their own distinctive beliefs and styles as well as professional and personal agendas. Thus, it may not be easy to bring them on board, and it is a real challenge in almost every case to keep up their commitment. (Dörnyei, 2007: 188f)

In SLA research, questions to do with teacher participant recruitment, selection and long-term commitment in classroom research have been discussed for quite some time. A study by Spada et al. (1996) focused specifically on the selection and trust-building of teacher participants in the context of English-as-second language (ESL) primary schools in Canada. Their research focused on the effect of form-focused instruction and error correction on French-speaking primary-school pupils' learning of ESL, using a quasi-experimental design involving three phases: description correlation - experimental treatment, the latter being delivered by the classroom teachers rather than the researchers. Importantly, for the recruitment of teachers for Spada et al.'s study, schools approached the researchers rather than the other way around, and their teacher participants were recruited from the researchers' professional networks, including former students. Following extensive school- and classroom observation (i.e. the descriptive phase), a further selection of focal teachers was then made: '[w]e try to select teachers whose characteristics and previous teaching behaviors match the goals of a particular study' (Spada et al., 1996: 38), almost always following extensive observation. This selection criterion appears particularly suitable in Spada et al.'s studies as it was the teachers who delivered the quasi-experimental intervention in the final phase. The publication provides no statistics of the number of teachers recruited and selected for their studies but provides a list of factors that contributed to the successful cooperation with their teacher participants: (a) treating them as colleagues whose knowledge and experience is highly and explicitly valued by the researchers, (b) conducting silent observation, including lunchbreaks and recess to build trust, (c) collaboration with school boards and local ESL teachers' associations, giving workshops as in-service training for teachers, (d) providing teacher-friendly presentations of research results and (e) publishing in professional teaching journals. 
In another study focusing on participant attrition in classroom research, Rossiter (2001) describes the fluidity of teacher and student participants in a study of 46 adult ESL students in Canada, all immigrants or refugees, attending a full-time course with planned data collection over 15 weeks. Rossiter lists and discusses a range of challenges encountered, including teacher fluidity. The research schedule spanned the course of one year, and arrangements were initially made so that one and the same teacher was planned to teach the group of students over that year. However, due to a decrease in programme enrollment and a lack of qualified ESL teachers, three different teachers (instead of one) ended up in teaching the group. All three consented to being part of Rossiter's study, but the third teacher showed no interest in the research, which affected the quality of the research in that teaching logs and audio-recordings of classroom activities ended up being incomplete.

In the following, we aim to contribute to the research-methodology literature by elaborating on how we brought secondary school teachers 'on board' (Dörnyei, 2007: 189), how we then made the selection, i.e. reduction, of the teachers to be engaged as focal teachers and the extent to which we managed to 'keep up' (Dörnyei, 2007: 189) their commitment over a data-collection period of two and half years. The fact that both projects involve teams of researchers collecting data in different sites resulted in one of the projects experiencing fluidity not only among participating teachers and students but also in the team of researchers over time. We thus bring in a new category of participant, namely researcher in team-based research. We also go beyond the previous research reviewed above by providing statistics on the fluidity of the teacher and researcher participants in the two projects, to which we now turn.

\section{The Two Projects}

\section{MultiLingual Spaces}

MultiLingual Spaces responds to a need for research in language-diverse English-as-an-additional language (EAL) classrooms and migrant students' learning of EAL in classrooms where monolingual, English-Only practices have been the ideal for a long time (Källkvist et al., 2017). MultiLingual Spaces builds on research in psycholinguistics, bilingualism and additional-language education, which can contribute to explaining the frequent Swedish-English translanguaging found in many EAL classrooms in Sweden (Beers Fägersten, 2012; The Swedish Schools Inspectorate, 2011), despite the English-Only ideal. Launched in 2017, MultiLingual Spaces was funded by the Swedish Research Council for four years, focusing on language practices in multilingual EAL classrooms in school years 7-9 in Sweden, which mark the end of compulsory school.

MultiLingual Spaces engaged four senior researchers in two different, geographically distant sites. Each of the two sites engaged two different 
secondary schools over a period of two and a half years. Similar to many previous classroom studies (Spada, 2005), MultiLingual Spaces involves two phases: a descriptive, linguistic-ethnographic (Copland \& Creese, 2015) phase, followed by an experimental (intervention) phase. The descriptive phase served as an opportunity to collect linguisticethnographic data in intact, language-diverse classes taught by experienced EAL teachers and to build trust between researchers, teachers, students and other school staff. On the completion of the descriptive phase, MultiLingual Spaces developed teaching materials for the experimental phase, in which pedagogical translanguaging was introduced as part of quasi-experimental interventions in six purposively selected intact classes, taught by the researchers in the presence of the teachers. Pedagogical translanguaging was introduced by providing vocabulary lists for each minority language represented in the classes involved and by inviting students to translanguage using their full language repertoires. Focusing on vocabulary, qualitative and quantitative data on students' vocabulary learning in EAL were collected along with qualitative data addressing ideologies of language learning and attitudes to classroom language practices.

\section{The Language Introduction Project}

The Language Introduction Project (LangIntro) also runs over four years, beginning in 2018, in three research sites, with a main data collection of two and a half years in two of the sites and of one and a half years in one site. The aim of LangIntro is to investigate several (inter)related research questions about recently arrived students' language development, academic development (disciplinary literacy) and social inclusion in the Swedish upper-secondary school Language Introduction Programme (LIP). ${ }^{1}$ LangIntro builds on research identifying flexible multilingual practices, including pedagogical translanguaging, in classrooms as beneficial for the development of disciplinary (bi)literacy (García, 2009; Hornberger, 2003; Hornberger \& Link, 2012; Schleppegrell, 2004, 2013) and on research on inclusion and inclusive education (Kugelmass, 2006; Nilsson Folke, 2017). LangIntro fills a research gap at the upper-secondary school level and responds simultaneously to a grassroots' call for research to draw on, as LIP rapidly grew to become the fourth largest programme in upper-secondary school in the academic year 2016/2017, following increasing migration flows, especially in 2015 (SNAE, 2018; Swedish Research Council, 2015a: 42-43, 2015b: 52).

LangIntro has a complex interdisciplinary research design, both in terms of researchers and participants as well as in terms of types of data collection for individual studies. Five senior researchers, at three different universities distantly apart, and four $\mathrm{PhD}$ students are all conducting individual studies. The common methodological denominator is the 
combination of linguistic-ethnographic methods such as participant observations, questionnaires and interviews (Copland \& Creese, 2015) with the collection and analysis of quantifiable linguistic data (such as student texts, classroom recordings) and assessment data of several kinds (such as data on the students' prior schooling, their individual study plans and their grades). In one of the participating schools, in close collaboration with a teacher, a quasi-experimental intervention study focusing on disciplinary literacy in the social sciences is conducted. Further details regarding LangIntro and MultiLingual Spaces are provided in Table 3.1.

Teachers serve as key participants, with both projects aiming to map experienced teachers' language practices in multilingual classrooms. Below, we describe how we approached schools and teachers in our search

Table 3.1 Description of the MultiLingual Spaces and LangIntro Projects

\begin{tabular}{|c|c|c|}
\hline & MultiLingual Spaces & LangIntro \\
\hline Sites & $\begin{array}{l}\text { Four secondary schools (years 7-9) } \\
\text { in two sites distantly apart }\end{array}$ & $\begin{array}{l}\text { Four upper-secondary schools in three } \\
\text { different sites distantly apart }\end{array}$ \\
\hline Timeframe & 2017-2020 & 2018-2021 \\
\hline $\begin{array}{l}\text { Theoretical } \\
\text { frames }\end{array}$ & $\begin{array}{l}\text { Linguistic Ethnography } \\
\text { Pedagogical translanguaging } \\
\text { Nexus Analysis } \\
\text { Vocabulary learning }\end{array}$ & $\begin{array}{l}\text { Linguistic Ethnography } \\
\text { Inclusive education (including } \\
\text { Pedagogical translanguaging) } \\
\text { Systemic Functional Linguistics }\end{array}$ \\
\hline Aims & $\begin{array}{l}\text { Research language practices } \\
\text { among experienced EAL teachers } \\
\text { and EAL students (age 13-16); } \\
\text { Research ideologies } \\
\text { underpinning teachers' and } \\
\text { students' language practices; } \\
\text { Research the effect of } \\
\text { monolingual, bilingual and } \\
\text { multilingual language practices } \\
\text { on teacher-student and student- } \\
\text { student classroom interaction } \\
\text { and on student learning of } \\
\text { English vocabulary. }\end{array}$ & $\begin{array}{l}\text { Research language practices among } \\
\text { subject teachers and newly arrived } \\
\text { students (age 16-19); } \\
\text { Research students' language } \\
\text { development, development of } \\
\text { disciplinary literacy and assessment; } \\
\text { Research ideologies and organisation } \\
\text { of education underpinning teachers', } \\
\text { principals' and students' language } \\
\text { practices; conduct an intervention study } \\
\text { with a focus on disciplinary literacy. }\end{array}$ \\
\hline Methods & $\begin{array}{l}\text { Descriptive phase: } \\
\text { Questionnaires, ethnographic } \\
\text { classroom observation, } \\
\text { photography, artifacts, classroom } \\
\text { video-recordings and audio- } \\
\text { recorded interviews. } \\
\text { Experimental phase: Quasi- } \\
\text { experimental teaching } \\
\text { interventions running over three } \\
\text { weeks in six intact classes. }\end{array}$ & $\begin{array}{l}\text { Questionnaires, ethnographic classroom } \\
\text { observation, photography, artifacts, } \\
\text { video- and audio-recordings, interviews, } \\
\text { student texts, assessment and grade } \\
\text { data, quasi-experimental teaching } \\
\text { intervention. }\end{array}$ \\
\hline Team & $\begin{array}{l}\text { Four associate professors with } \\
\text { tenure (at two universities in } \\
\text { different parts of Sweden) }\end{array}$ & $\begin{array}{l}\text { Four full professors with tenure, one } \\
\text { post-doctoral researcher, four PhD } \\
\text { candidates (at three universities in } \\
\text { different parts of Sweden) }\end{array}$ \\
\hline Funding & The Swedish Research Council & The Swedish Research Council \\
\hline
\end{tabular}


for suitable research contexts and - in the case of LangIntro - how research participants were recruited.

\section{Recruiting and Selecting Teacher and Researcher Participants}

The selection of teacher participants has been elaborated on in the methodology literature reviewed above, with Spada (2005: 333) describing it as 'complicated, particularly when working in intact classrooms'. Both MultiLingual Spaces and LangIntro are based on the epistemology that underpins Linguistic Ethnography (Copland \& Creese, 2015), thus involving context-sensitive qualitative data. Therefore, focal schools, teachers, classes and students were purposively selected following 'principled decisions' (Dörnyei, 2007: 126). While Spada et al. (1996), reviewed above, describe a context in which teachers approached the researchers to initiate research, both MultiLingual Spaces and LangIntro were offered funding prior to approaching schools. We now turn to describing the decisions made by the research teams and the criteria used for selecting teacher participants, beginning with MultiLingual Spaces.

\section{MultiLingual Spaces}

MultiLingual Spaces involved four senior researchers for the full duration of the project, based in two different sites: Site 1 and Site 2. When recruiting and selecting schools and teachers, MultiLingual Spaces made the following principled decisions: (i) To facilitate ethnographic data collection, schools needed to be within commuting distance from the researchers' universities, (ii) to qualify as a multilingal class, intact classes should include at least five students who were regular users of a minority language in addition to Swedish (the school language), (iii) teachers should volunteer and express an intention to participate over the course of two and a half years, (iv) teacher participants should preferably involve more than one gender and (v) to address the issue of participant attrition evident in prior, long-term school research, a redundant number of 7 teachers and 14 of their intact classes in 4 different schools were recruited for the descriptive phase. In addition, the principals consented to the schools' participation and committed to participate in case their teachers were to attrite. The target sample for the the experimental phase was four focal teacher participants at four different schools in four different locations, including a total of six intact classes. These were to be evenly distributed across Site 1 and Site 2 .

Approaching schools and teachers was done differently in the two sites due to differing profiles of the two universities involved. The university in Site 2 had long had teacher-education programmes and school research, whereas the university in Site 1 did not. The Site- 2 researchers therefore had a professional network of secondary school teachers from whom they 
quickly recruited three teachers at two schools (the aim being to retain two of them for the intervention phase). In the absence of a similar network of EAL teachers, the Site-1 researchers went about their sampling of schools and teachers differently: They wrote to the school authorities in two municipalities, describing the research project and asking for contacts with school leaders in multilingual schools. This resulted in the engagement of a large, urban multilingual and multicultural school where most of the data were collected. In the absence of a response from the second municipality, the second school in Site 1 was in the end recruited through the researchers' private networks, resulting in the engagement of two teachers at an urban school, in which there was less language diversity. As the MultiLingual Spaces team in Site 1 did not know the teachers prior, they engaged greater redundancy than in Site 2: Four volunteer teachers were engaged in Site 1 (the aim being to retain two for the intervention phase), two in each of the two schools so that they could share the experience of having researchers present in some of their classes. Also, this way, the researcher participants (two) matched the number of teacher participants (two) in both schools. Of the seven teachers recruited by MultiLingual Spaces, three were lead teachers (förstelärare), in this case meaning that they had been reviewed by school administrators and promoted on the basis of their high-quality teaching skills.

\section{LangIntro}

Initially, LangIntro engaged four senior researchers in the research team, employed for the full duration of the project. The plan was also to affiliate a post-doctoral researcher and two $\mathrm{PhD}$ students. Once we learnt about the approval of our application, the recruitment of the two PhD students commenced; the post-doctoral recruitment had already started independently. Hence, we planned for an initial recruitment period of research participants, which would enable the project to start with a complete research team of seven researchers in autumn 2018. Below, we recount a somewhat different course of events.

Regarding the recruitment and selection of schools and teachers, the following principled decisions guided LangIntro: (i) Schools should offer LIP, (ii) schools should explicitly state that they offered language-developing education in all subjects, (iii) schools should be within commuting distance of the researchers' home universities, (iv) the principals should express interest in the project and $(\mathrm{v})$ individual teachers should be willing to volunteer over a long period of time (at most two and a half years). These criteria were in the end applied when selecting three of the participating schools - one of the schools did not have a policy offering language-developing education in all subjects (Criterion 2), but as there was established research collaboration between the school and one of the researchers and the other criteria were met, this school was still selected. 
The three other schools met all selection criteria. Initially, we approached the local municipality school offices, in order to reach out to all principals in the school districts located in the vicinity of the universities involved. After presenting the project in the municipalities and gaining their approval, all principals in schools offering LIP were approached and asked whether they were interested in participating after talking to their teacher staff. In one of the three research sites, one school meeting the above criteria was identified and selected. In yet another site, several schools expressed an interest in participating, and finally, two schools with different profiles (one reception school mainly focusing on Swedish as a second language and one offering all school subjects) were selected. In line with principles of ethnography, we invited all teachers who wished to participate to begin with. Thus, we had not decided in advance which teachers and classrooms were to become focal. Rather, the individual substudies conducted by the researchers were decided on only after initial analyses of teacher interviews and classroom observation from classrooms taught by the teacher participants. An additional factor guiding these principled decisions was whether the teacher and the researchers believed that the students in the classroom would consent to participate. From initially observing 38 classrooms, we gradually narrowed down the number of focal teacher participants to 10 .

\section{Fluidity of Teacher and Researcher Participants Over Time}

\section{MultiLingual Spaces: The descriptive phase}

In MultiLingual Spaces, the team of four researchers remained intact throughout the duration of the project, so participant fluidity applies to teachers (and student fluidity is beyond the scope of this chapter). Figure 3.1

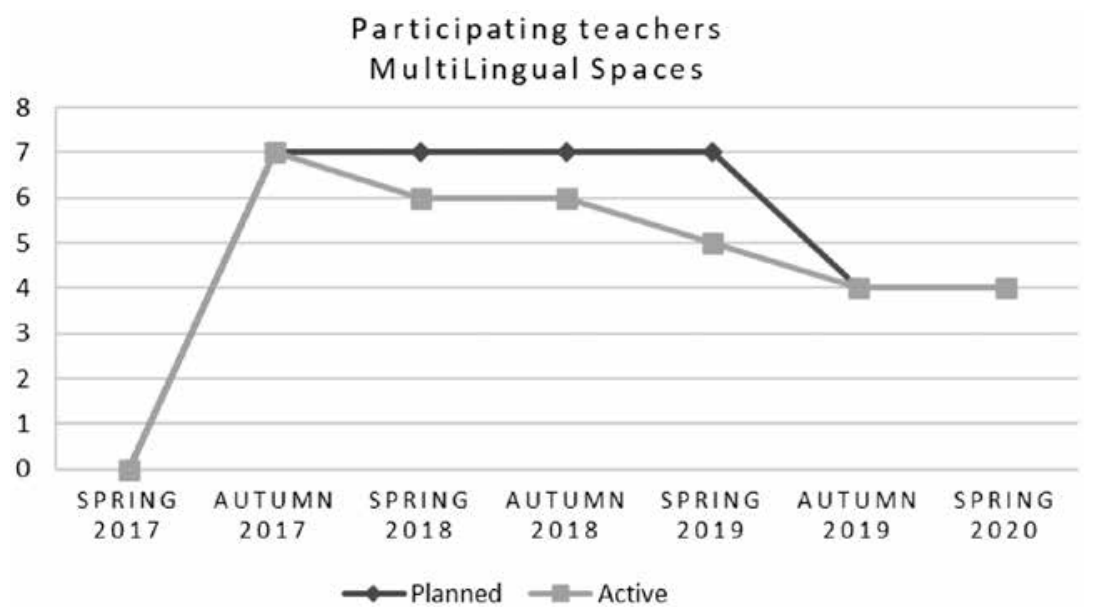

Figure 3.1 Number of teacher participants in MultiLingual Spaces over time 
illustrates attrition; there was attrition from seven to six teachers early on. This was due to one of the teachers withdrawing her consent to participate when learning that participation would involve video-recording in the classroom, as she had found video-recording in her classroom to be too obtrusive in a prior research project. At the beginning of data collection, MultiLingual Spaces thus engaged six teacher participants, all of whom were teaching EAL in multilingual schools in four different urban areas. As a token of gratitude and an opportunity for professional development, MultiLingual Spaces invited all six to join the biannual conference of Applied Linguistics organised by the Swedish Association of Applied Linguistics in 2018, which had the suitable theme of Language(ing) and Classroom Research.

The next case of attrition was a teacher in Site 1, who moved eight months after data collection began, leading to a long commute to his school. With the current shortage of qualified teachers, he was immediately offered employment in his new hometown. He left MultiLingual Spaces at the end of the descriptive phase (summer 2018). Besides losing a devoted teacher participant, the loss of this particular teacher led to all four teachers engaged during the intervention belonging to one gender (female).

\section{MultiLingual Spaces: The experimental phase}

MultiLingual Spaces entered the experimental phase with a retention level of five teachers (three in Site 1 and two in Site 2) while needing to retain four. The fifth teacher remained in the background as a backup should one of the other two Site-1 teacher participants leave.

At the time, there were financial cutbacks, which affected Site 1 in the shape of larger EAL classes in one of the two focal schools. This change was made in the summer break, resulting in one of the intact classes that was targeted for the intervention no longer existing in the autumn semester 2019, which is when the intervention was to take place. This led to the Site-1 researchers, on short notice, needing to involve a new intact class, which was new also to the focal teacher. Engaging the new intact class meant commencing a new descriptive, trust-building phase to collect observation data and pave the way for conducting the intervention. As the experimental phase began, there was no more teacher-participant attrition. The intervention covered six English lessons over three consecutive weeks; it was designed by the research team and was subsequently taught by one of the researchers in the presence of the teacher, and the other researcher, who was in charge of video-cameras and audio-recorders. The length of the intervention (three weeks) caused a further delay in Site 1. We elaborate on this below, but first, we present statistics for researcher and teacher fluidity in LangIntro. 


\section{LangIntro: Teacher participant fluidity}

Teacher participant fluidity manifested itself mainly in three ways in LangIntro. First, the purposeful selection of focal teachers and classes to engage with in the individual studies had led to a lower number of teacher participants over time, which was according to plan. Second, three of the principals initially participating either changed jobs or delegated the leadership of the LIP to a deputy principal. Support from the principal was an important selection criterion for the participating schools. However, as the new principals expressed their equally strong support of the project, we did not experience any challenges due to these changes in school leadership.

Third, there was attrition among the selected focal teacher participants. At times, they cancelled classroom observations and other appointments with the researcher participants due to illness or changes in their schedules reflecting the realities of classrooms, but this did not interfere with data collection. Two of the 10 focal teachers selected, however, did not participate for the full duration of data-collection phase, thus affecting the implementation of the project in different ways. In the first case, one of the two focal teacher participants in the school where the intervention study was conducted took leave during data collection. Our aim was to be able to select one of the focal teachers as a participant in the intervention study. Hence, the leave just prior to the collaborative planning phase of the intervention commenced affected the data collection directly, resulting in automatically selecting the teacher who did not take leave. In the second case, one of the focal teachers changed jobs. On the whole, however, the purposeful selection of a redundant number of potential focal teacher participants provided the project with rich longitudinal data to analyse according to plan. None of the participating teachers ended their participation on other grounds; they were thus engaged throughout the data-collection phase.

\section{LangIntro: Researcher participant fluidity}

In ethnographic studies, researchers play an important role as social agents alongside other participants (Copland \& Creese, 2015). The planned number of researchers and $\mathrm{PhD}$ students in the LangIntro project was seven: five senior and two junior researchers (PhD students). However, for several reasons, the project can initially be characterised by high researcher fluidity. In the first six months (January-June 2018), the PI and one of the senior researchers were, according to plan, actively involved, creating information leaflets, designing questionnaires and interview guides, applying for ethics permission, approaching prospective participants and making calls for $\mathrm{PhD}$ student positions, which involved reviewing applications and interviewing candidates. The plan was to create pairwise teams of one senior and one junior researcher, or two senior researchers responsible for one school each, and to start data collection in autumn 2018, immediately following the summer break, with the full number of researcher participants. However, 


\section{Participating researchers LangIntro}

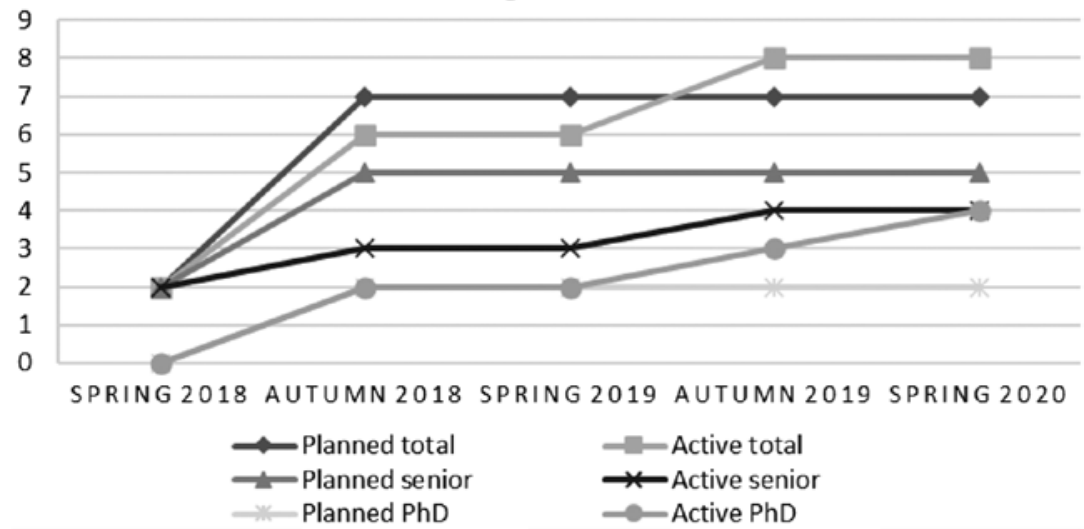

Figure 3.2 Number of researcher participants in LangIntro over time

two of the senior researchers were not able to join the research team as planned. Further, the call for $\mathrm{PhD}$ posts rendered only one candidate who could fill the post as project researcher, instead of two. However, the postdoctoral researcher and one additional $\mathrm{PhD}$ student were affiliated to the team, which, thus, in autumn 2018, consisted of three operative senior and two junior PhD researchers (see Figure 3.2), commencing data collection in three of the participating four schools.

As shown in the two top lines in Figure 3.2, we planned to have a total of seven researchers (five senior and two junior PhD students) from autumn 2018 but ended up with a total of eight researchers (four senior and four junior PhD students; see also the four bottom lines in Figure 3.2) from autumn 2019. By this time, one of the initially absent senior researchers joined the team, while the other had retired, and we had successfully recruited two new $\mathrm{PhD}$ students as junior researchers and were able to commence data collection also in the fourth school. Thus, the initial fluidity of researcher participants in the end resulted in a greater number of active researchers. The data collection in the fourth school was postponed due to the delayed recruitment of the two new PhD students. However, as we were able to recruit not one but two new team members, we were able to intensify data collection in the fourth school, thus reducing the effect on the general data collection in LangIntro to a minimum.

\section{Consequences and Outcomes of Participant Fluidity}

\section{MultiLingual Spaces}

As explained above, in MultiLingual Spaces, there were delays due to the attrition of one teacher in Site 1 at the end of the descriptive phase. One of his classes was scheduled to participate in the intervention in spring 
2019. As the teacher replacing him was a fresh graduate from university, she did not meet the criteria of being qualified and experienced in teaching language-diverse EAL classes, so MultiLingual Spaces did not invite her to participate. In the end, the attrition of one teacher at the end of the descriptive phase led to (i) the loss of the only male teacher participant in the intervention phase, (ii) the loss of one intact class that was scheduled to participate in the intervention, which led to a delay of the completion of the intervention by two months and (iii) researcher time was needed for an additional descriptive phase to build trust with students in the new intact class.

The attriting teacher announced his change of jobs well ahead of time (as soon as he knew about it), which enabled the Site-1 researchers to adjust their data-collection schedule by taking the opportunity of designing a case study of the attriting teacher and his students. Case studies are suited to developing the in-depth understanding of complex, dynamic entities in their specific contexts (Duff, 2008) of which language-diverse classrooms are perfect examples (Baker \& Wright, 2017; Lin, 2008). The attriting teacher was very successful in explaining the value of research to his students, motivating them to participate in interviews. As part of the case study (Källkvist et al., 2019, 2020), interviews were carried out with the teacher, the team of English teachers at the school and 19 students who were regular users of a minority language and of Swedish.

In Site 2, where the university had a well-established network of teachers, the descriptive and experimental phases involving two focal teachers progressed entirely according to plan, and data collection was complete in December 2019. In Site 1, the experimental phase was also scheduled to end in December 2019 but was delayed until February 2020 due to scheduling clashes; the intervention was to be carried out in six consecutive lessons over three weeks in two different intact classes in November 2019, but as classes were scheduled at the same time in both schools, one of the interventions had to be re-scheduled for December 2019. As December approached, another delay presented itself in that two English lessons were cancelled due to the school's Christmas festivities. This school also had a habit of breaking its normal schedule for theme-based teaching and learning, which made it harder to find the three consecutive weeks of six uninterrupted English lessons that the intervention required. As a result, the sixth and final MultiLingual Spaces intervention was run from mid-January until early February 2020, delayed by six weeks. As is evident in the classroom researchmethodology literature, teacher participant attrition as well as delays in data collection were expected and came as no surprise. The adjustments in the data-collection schedule needed were accommodated within the four-year timeframe of the project thanks to Site-1 researchers' flexibility. 


\section{LangIntro}

Aside from the already mentioned occasional changes in the teacher participants' schedules due to illness or the like, LangIntro experienced only the two cases of teacher participant attrition described above. Fortunately, as there were two potential teachers for the intervention study, it was possible to conduct the intervention. The main effect was, thus, that LangIntro did not actively select one of the teachers for the study; rather, the participating teacher was automatically selected through teacher attrition. Thus, in this case, redundancy in the number of focal teachers proved crucial. Regarding the focal teacher who changed jobs, LangIntro experienced teacher participant attrition that reduced opportunities to conduct data collection according to plan, as the plan was to follow the teacher for a longer period.

In order to retain teacher participants' engagement throughout the project, Lang-Intro researchers visited the schools regularly, participated in staff meetings, had informal conversations during lunch and other breaks, invited some focal teacher participants to conferences and offered the schools in-service education for LIP teachers, as well as had regular email contact with the focal teachers.

Researcher participant fluidity also had an impact on (1) the planned data-collection schedule and (2) the planned pairwise organisation of researchers working in different schools. Most notably, LangIntro started data collection a year later than scheduled in the fourth participating school. However, even though this caused a delay in the project as a whole, there were also some positive outcomes of this delay. For example, as we were able to employ two instead of one PhD student and as the PI had already established contact with the school, we were able to recruite teacher participants rapidly, thus speeding up the otherwise time-consuming process of establishing contacts. LangIntro, thus, also experienced researcher participant reinforcement through the recruitment and affiliation of four rather than two PhD students.

\section{Discussion: Fluidity and Time in MultiLingual Spaces and LangIntro}

LangIntro and MultiLingual Spaces are grounded in Linguistic Ethnography, involving multi-sited secondary school classroom research over a period of two and a half years, and were conducted by teams of researchers in different locations. Both recruited school, teacher and student participants following funding approval that was external to the PIs' universities and ethics clearance. LangIntro's design required the recruitment not only of teachers but also junior researchers. We now revisit the aim of this chapter by discussing the amount of redundancy 
among teacher participants needed and the impact of teacher and researcher fluidity on the data eventually collected and the time needed to collect them.

As to teacher participant attrition, MultiLingual Spaces initially engaged seven teachers for its descriptive (observation) phase, with the target of retaining four focal teachers for its experimental phase. There was attrition of two teachers, one withdrawing her consent as she found classroom video-recording too obtrusive, and the other due to moving to a different town and therefore changing jobs. In LangIntro, there was attrition of two out of the ten focal teachers initially engaged, causing minor adjustments to the data-collection schedule. The recruitment of $\mathrm{PhD}$ students (who, in Sweden, have salaried university positions) caused delays in the start-up of LangIntro's data-collection schedule in one of the schools. This required flexibility on the part of the PI, who needed to join the $\mathrm{PhD}$ students in three schools.

Measures were taken in order to motivate teachers and junior researchers to remain committed. One key strategy was pairwise constellations of teachers who were new to research. In MultiLingual Spaces Site 1, where the researchers and teachers did not know each other from before, a principled decision was made to engage two teachers at each school. This ensured the redundancy needed, but, equally importantly, teachers could turn to each other for reflection on their roles as research participants as teaching in the presence of researchers may be obtrusive (Sundqvist et al., 2019). In addition, the pairwise constellation created the matched number of two researchers and two teachers in both schools in Site 1. Pairwise work was key in LangIntro as well in providing support for junior researchers, who were all joined by a senior researcher. Another strategy, mentioned in prior research (Spada et al., 1996), was to invite the teacher participants to one or two research conferences over the course of the four years.

When it comes to the effect of teacher participant attrition on the data gathered, previous research (Rossiter, 2001) has shown that attrition can compromise the quality of data in longitudinal studies, in Rossiter's study in the shape of incomplete data. Teacher attrition in LangIntro and MultiLingual Spaces affected data collection in the following ways: LangIntro collected the same amount of data that was initially planned, and in one instance, teacher participant attrition automatically selected which teacher in the end became the focal teacher. In MultiLingual Spaces, attrition led to a larger data set, an additional case study, than originally planned. It also led to Site-1 researchers investing additional time in the descriptive phase when having to engage a new intact focal class for the intervention following budget cuts in one of its schools.

Delays in collecting data were expected in both projects. In LangIntro, the postponed successful recruitment of all the participating PhD students 
delayed the start of data collection in one of the schools. Having approached the municipality and the school early on, there was a risk of losing the principals' and some of the teachers' interest and commitment to participate. In order to keep up their engagement, the PI was in regular touch with the school throughout the year and invited a couple of teachers to participate in a conference organised by the authors. This is an example of the flexibility required in classroom research (Schachter \& Gass, 1996) and the need for a 'plan B' (Blommaert \& Dong, 2010: 22, emphasis in original).

In MultiLingual Spaces, flexibility was needed to conduct all six intervention studies, the greatest challenge being the scheduling of the threeweek intervention involving six consecutive English lessons in one of the Site-1 schools. The research design involving intervention case studies was important to MultiLingual Spaces as it met calls made in the literature for 'systematic longitudinal, interventionist studies that can work on refining bilingual classroom strategies and pedagogies to achieve the goals deemed worthwhile in specific contexts' (Lin, 2008: 284). In order to ensure the flexibility needed, Site-1 researchers had a Plan B as well as C and D, and the PI had no scheduled teaching at her university over a period of four months, apart from teaching the intervention lessons themselves over the three weeks.

Finally, the opportunity of four-year funding provided time space to conduct classroom research involving both a descriptive and an experimental phase of the kind called for by multilingual-education researchers (Baker \& Wright, 2017; Juvonen et al., 2020; Lin, 2008). Preparing for and conducting longitudinal intervention-data collection was particularly time-consuming, as noted by Ortega and Byrnes (2008).

\section{Acknowledgements}

We gratefully acknowledge funding from The Swedish Research Council (MultiLingual Spaces: VR-UVK 2016-03469; LangIntro: VR-National Research Programme Migration and Immigration 2017-03566). Our gratitude extends also to our co-researchers, who not only consented to the publication of this chapter and thus became our objects of study, but who also, together with teacher, student and school leader participants, made this team-based school research possible.

\section{Note}

(1) In Sweden, almost all students attend upper-secondary school. All adolescent migrants aged 16-19 years, irrespective of their previous school experience, are in Sweden placed in this transitional programme. The aim of LIP is to teach students enough Swedish as well as to obtain grades in at least eight school subjects at the compulsory school level in order to qualify for mainstream upper-secondary school education. LIP, thus, serves a gatekeeping function. 


\section{References}

Baker, C. and Lewis, G. (2015) A synthesis of research on bilingual and multilingual education. In W.E. Wright, S. Boun and O. García (eds) Handbook of Bilingual and Multilingual Education (pp. 109-126). Maldone, MA: Wiley Blackwell.

Baker, C. and Wright, W.E. (2017) Foundations of Bilingual Education and Bilingualism (6th edn). Bristol: Multilingual Matters.

Barwell, R. (2019) Language diversity in classroom settings. In K. Tusting (ed.) The Routledge Handbook of Linguistic Ethnography (pp. 273-285).

Beers Fägersten, K. (2012) Teacher discourse and code choice in a Swedish EFL classroom. In B. Yoon and H.K. Kim (eds) Teachers' Roles in Second Language Learning: Classroom Applications of Sociocultural Theory (pp. 81-98). Hershey, PA: IGI Global.

Blommaert, J. and Dong, J. (2010) Ethnographic Fieldwork: A Beginner's Guide (1st edn). Bristol: Multilingual Matters.

Cohen, L., Manion, L. and Morrison, K. (2011) Research Methods in Education. London: Routledge.

Copland, F. and Creese A. (2015) Linguistic Ethnography: Collecting, Analysing and Presenting Data. London: Sage.

Creese, A. and Blackledge, A. (2010) Translanguaging in the bilingual classroom: a pedagogy for learning and teaching? The Modern Language Journal 94 (1), $103-115$.

Cummins, J. (2018) Urban multilingualism and educational achievement: Identifying and implementing evidence-based strategies for school improvement. In P. Van Avermaet, S. Slembrouck, K. Van Gorp, S. Sierens and K. Maryns (eds) The Multilingual Edge of Education (pp. 67-90). London: Palgrave Macmillan.

Dörnyei, Z. (2007) Research Methods in Applied Linguistics. Oxford: Oxford University Press.

Duff, P.A. (2008) Case Study Research in Applied Linguistics. London: Routledge.

Duff, P. and Early, M. (1996) Problematics of classroom research across sociopolitical contexts. In J. Schachter and S. Gass (eds) Second Language Classroom Research: Issues and Opportunities (pp. 1-30). Mahwah, NJ: Lawrence Erlbaum.

García, O. (2009) Bilingual Education in the 21st Century: A Global Perspective. Malden, MA: Wiley-Blackwell.

Hornberger, N.H. (2003) Continua of Biliteracy an Ecological Framework for Educational Policy, Research, and Practice in Multilingual Settings. Clevedon: Multilingual Matters.

Hornberger, N.H. and Link, H. (2012) Translanguaging in today's classrooms: A biliteracy lens. Theory Into Practice 51 (4), 239-47.

Juvonen, P., Eisenchlas, S.A., Roberts, T. and Schalley, A.C. (2020) Researching social and affective factors in home language maintenance and development: A methodology overview. In S.A. Eisenchlas and A.C. Schalley (eds) Handbook of Home Language Maintenance and Development (pp. 38-58). Berlin: De Gruyter Mouton.

Källkvist, M., Gyllstad, H., Sandlund, E. and Sundqvist, P. (2017) English Only in multilingual classrooms? LMS - Lingua 4, 27-31.

Källkvist, M., Gyllstad, H., Sandlund, E. and Sundqvist, P. (2019) English Only in multilingual classrooms? A study of students' self-reported practices and attitudes. American Association for Applied Linguistics conference, Atlanta, GA, 9-12 March 2019.

Källkvist, M., Gyllstad, H., Sandlund, E. and Sundqvist, P. (2020) Students and their teacher as language-policy makers in two multilingual, secondary-school English classrooms. ASLA-symposiet 2020, The Swedish Association of Applied Linguistics, Gothenburg University, 23-24 April.

Kugelmass, J.W. (2006) Sustaining cultures of inclusion: The value and limitations of cultural analyses. European Journal of Psychology of Education XXI (3), 279-292. 
Lightbown, P. and Spada, N. (2019) In it together: Teachers, researchers and classroon SLA. Plenary lecture, American Association of Applied Linguistics conference, Atlanta, 9-12 March.

Lin, A.M. (2008) Code-switching in the classroom: Research paradigms and approaches. In N.H. Hornberger and K. King (eds) Research Methods in Language and Education (pp. 273-286). New York: Springer.

Mackey, A. and Gass, S. (2005) Second Language Research: Methodology and Design. Mahwah, NJ: Lawrence Erlbaum.

Nilsson Folke, J. (2017) Lived Transitions - Experiences of Learning and Inclusion Among Newly Arrived Students. Stockholm: Stockholm University.

Ortega, L. and Byrnes, H. (2008) The Longitudinal Study of Advanced L2 Capacities. New York: Routledge.

Rossiter, M.J. (2001) The challenges of classroom-based SLA research. Applied Language Learning 12 (1), 31-44.

Schachter, J. and Gass, S. (1996) Second Language Classroom Research: Issues and Opportunities. Mahwah, NJ: Lawrence Erlbaum.

Schleppegrell, M.J. (2004) The Language of Schooling: A Functional Linguistics Perspective. Mahwah, NJ: Lawrence Erlbaum Associates.

Schleppegrell, M.J. (2013) The role of metalanguage in supporting academic language development. Language Learning 63 (1), 153-70.

SNAE (2018) Uppföljning av språkintroduktion. Beskrivande statistik på nationell nivå och nyanlända elevers övergångar till och från språkintroduktion [Swedish National Agency of Education, Report 46. Follow-up of LIP. Descriptive Statistics on national level and newly arrived students' transfer to and from LIP]. Stockholm: SNAE.

Spada, N. (2005) Conditions and challenges in developing school-based SLA research programs. The Modern Language Journal 89 (3), 328-338.

Spada, N., Ranta, L. and Lightbown, P.M. (1996) Working with teachers in Second Language Acquisition research. In J. Schachter and S. Gass (eds) Second Language Classroom Research (pp. 31-44). Mahwah, NJ: Lawrence Erlbaum Associates.

Sundqvist, P., Sandlund, E., Källkvist, M., Fredholm, K. and Dahlberg, M. (2019) Ömsesidighet i framtidens praktiknära språkklassrumsforskning: ASLA-symposiets panelsamtal med forskare, lärare och elever [Reciprocity in future practice-oriented classroom research: The Panel Discussion at the ASLA Symposium]. In Ljung Egeland, B., Roberts, T., Sandlund, E. and Sundqvist, P. (eds) Klassrumsforskning och språkande: Rapport frä ASLA-symposiet i Karlstad, 12-13 april 2018 [Classroom Research and Languaging: Report from the ASLA Symposium at Karlstad, 12-13 April], (pp. 19-42). Karlstad: Karlstad University Press.

Swedish Research Council (2015a) Forskningens framtid! Ämnesöversikt 2014 Utbildningsvetenskap [The Future of Research! Review of Research in Education 2014]. Stockholm: Swedish Reserach Council.

Swedish Research Council (2015b) Forskningskvalitet för framtiden. Redovisning av regeringsuppdrag (U2015/1362/F) [Research Quality for the Future. Review Commissioned by the Government]. Stockholm: Swedish Reserach Council.

The Swedish Schools Inspectorate (2011) Engelska i grundskolans årskurser 6-9 [English in Compulsory School Years 6-9]. Stockholm: The Swedish Schools Inspectorate. 